Illinois State University

ISU ReD: Research and eData

Theses and Dissertations

7-28-2021

\title{
Mediation Among Depression, Acceptability of Emotions, Emotional Intensity and Emotional Disclosure
}

Brandie Vera

Illinois State University, brandievera5@gmail.com

Follow this and additional works at: https://ir.library.illinoisstate.edu/etd

\section{Recommended Citation}

Vera, Brandie, "Mediation Among Depression, Acceptability of Emotions, Emotional Intensity and Emotional Disclosure" (2021). Theses and Dissertations. 1476.

https://ir.library.illinoisstate.edu/etd/1476

This Thesis is brought to you for free and open access by ISU ReD: Research and eData. It has been accepted for inclusion in Theses and Dissertations by an authorized administrator of ISU ReD: Research and eData. For more information, please contact ISUReD@ilstu.edu. 


\section{MEDIATION AMONG DEPRESSION, ACCEPTABILITY OF EMOTIONS, EMOTIONAL INTENSITY AND EMOTIONAL DISCLOSURE}

\section{BRANDIE C. VERA}

45 Pages

The present study discussed talking about emotions with other people and the important role in emotional recovery (Rimé, 2009). Individuals with depression, however, have been shown to disclose less personal information than individuals without depression (Kahn \& Garrison, 2009). Little is known about the roles of acceptance of emotions and emotional intensity in the association between depression symptoms and emotional disclosure. The degree to which one believes their emotions are acceptable and the perceived intensity of emotional events might be mediators of the depression-disclosure relation. The hypotheses of the study include: Depressive symptoms will be negatively associated with emotional disclosure. Individuals reporting more depression symptoms will experience less subjective intensity of emotion in response to a real-life unpleasant event they are asked to recall. Individuals reporting more depression symptoms will view emotions concerning the negative event as less acceptable. The negative relationship between depression symptoms and emotional disclosure will be mediated by (a) acceptability of emotions and (b) emotional intensity. The study included 230 participants (college students from the Department of Psychology Participant Pool) who are at least 18 years of age. The Patient Health Questionnaire was used to measure the participant's severity of depression. Participants were then instructed to write about a time when they felt sad in the past month in as much detail as possible. Next, participants rated the intensity and 
negativity of the sad event. Trained, external raters blind to other study data also rated the intensity and negativity of participants' sad event. Acceptability of emotions was measured using the acceptability subscale from the Meta Evaluation scale. Further, emotional disclosure was measured using three items from Garrison and Kahn's (2010) study. Results showed a negative relationship between depression and emotional disclosure; however, it is non-significant. Results also showed depression symptoms had a significant relationship with emotional intensity suggesting the higher the depression score, the higher emotional intensity according to participants emotional intensity self-reports and emotional intensity difference scores. Further, depression symptoms and acceptability of emotions had a negative and significant relationship. This suggest individuals with more depression symptoms are less likely to rate emotions as acceptable. Participants' emotional intensity self-reports and emotional intensity difference scores were also significant with emotional disclosure indicating higher intensity leads to higher likelihood of emotionally disclosing. Lastly, emotional intensity mediated the relationship between depression and emotional disclosure even when gender was used as control. Limitations, future directions, and implications are discussed.

KEYWORDS: Depression; emotional disclosure; emotional intensity; acceptability of emotions 
MEDIATION AMONG DEPRESSION, ACCEPTABILITY OF EMOTIONS, EMOTIONAL

INTENSITY, AND EMOTIONAL DISCLOSURE

BRANDIE C. VERA

A Thesis Submitted in Partial

Fulfillment of the Requirements

for the Degree of

MASTER OF SCIENCE

Department of Psychology

ILLINOIS STATE UNIVERSITY 
(C)2021 Brandie C. Vera 
MEDIATION AMONG DEPRESSION, ACCEPTABILITY OF EMOTIONS, EMOTIONAL INTENSITY, AND EMOTIONAL DISCLOSURE

BRANDIE C. VERA

COMMITTEE MEMBERS:

Jeffrey Kahn, Chair

Laura Finan 


\section{ACKNOWLEDGMENTS}

I am grateful to all of those with whom I have had the pleasure to work during this project. Each of the members of my thesis committee has provided me extensive personal and professional guidance. I would especially like to thank Dr. Jeffrey Kahn, the chair of my committee. I would also like to thank Dr. Laura Finan, committee member. Both have served as great teachers and mentors. I would also like to thank the undergraduate research assistants, Aaron Herr, Taylor Magerkurth, and Meera Shukla, who engaged in hours of training and coding data for my study. Thank you to everyone who has played a role throughout my academic career.

B. C. V 


\section{CONTENTS}

Page

ACKNOWLEDGMENTS

TABLES

FIGURES

CHAPTER I: INTRODUCTION 1

$\begin{array}{ll}\text { Emotional Disclosure } & 4\end{array}$

Depression and Emotion Disclosure $\quad 6$

The Present Study 9

CHAPTER II: METHOD 12

$\begin{array}{ll}\text { Participants } & 12\end{array}$

$\begin{array}{ll}\text { Measures } & 12\end{array}$

$\begin{array}{ll}\text { Depression Symptoms } & 12\end{array}$

Disclosure of Real-Life Event 13

$\begin{array}{ll}\text { Acceptability of Emotion } & 14\end{array}$

$\begin{array}{ll}\text { Emotional Disclosure } & 15\end{array}$

$\begin{array}{ll}\text { Procedure } & 16\end{array}$

$\begin{array}{ll}\text { Data Analysis Plan } & 17\end{array}$

$\begin{array}{ll}\text { CHAPTER III: RESULTS } & 18\end{array}$

$\begin{array}{ll}\text { Preliminary Findings } & 18\end{array}$

$\begin{array}{ll}\text { Main Analysis } & 20\end{array}$

Participant Self-Reports of Intensity $\quad 21$

$\begin{array}{ll}\text { Intensity Difference Scores } & 22\end{array}$ 
CHAPTER IV: DISCUSSION

Limitations and Future Research Directions

Implications for Counseling

REFERENCES

APPENDIX A: PARTICIPANT CONSENT FORM

APPENDIX B: DEBRIEFING 


\section{TABLES}

Table

Page

1. Reports of Scales: Correlations and Descriptive statistics $(\mathrm{N}=234)$

2. Report of Slopes: Coefficients and Standard Error 25

3. Report of Slopes: Coefficients and Standard Error 25

4. Report of Slopes with Gender as Covariate: Coefficients and Standard Error 26

5. Report of Slopes with Gender as Covariate: Coefficients and Standard Error 26 


\section{FIGURES}

$\begin{array}{lll}\text { Figure } & \text { Page }\end{array}$

1. The Parallel Multiple Mediation Model Expected in the Study 11

2. The Parallel Multiple Mediation Model with Emotional-Intensity Self-Reports 22

3. The Parallel Multiple Mediation Model with Emotional-Intensity difference scores 23 


\section{CHAPTER I: INTRODUCTION}

According to the Diagnostic and Statistical Manual of Mental Disorders (DSM-5), "common features of all depressive disorders is the presence of sad, empty, or irritable mood, accompanied by somatic and cognitive changes that significantly affect the individual's capacity to function" (American Psychiatric Association [APA], 2013, p. 155). According to Bieling and colleagues (2014), 17\% of people will experience depression at some point in their life. This high prevalence rate will continue to grow, and depression is expected to become the \#1 burden of disease worldwide by 2030. Most worrisome is the fact that many people with depression do not get the help or treatment they need- $-50 \%$ of individuals with depression receive no treatment at all (Kessler et al., 2003).

The burden of depression is especially hard on college students where depression is twice as common compared to the general population (American College Health Association, 2017). Similar to the general population, depression in college students is poorly managed with only half of depressed students receiving treatment (Zivin et al., 2009). The rate that depression is increasing in youth is significantly faster compared to older groups. An increase in depression was also seen in men, women, non-Hispanic white persons, lowest and highest income groups, and the highest education group (Weinberger et al., 2018). The prevalence of depression symptoms in 18 to 29 -year-old individuals is three times higher than the prevalence in individuals 60 years and older (Kessler et al., 2003). This research shows just how prevalent depression is in a variety of populations.

Depression, or more formally major depressive disorder (MDD), is characterized by the presence of one or more major depressive episodes (APA, 2013). A major depressive episode (MDE) consists of at least 2 weeks of depressed mood and/or loss of interest or pleasure in usual 
activities. The mood in a depressive episode is often described by the person as depressed, sad, hopeless, discouraged, "down in the dumps," or "blah" (APA, 2013). In other cases, a person may report an increase in irritability which is exhibited with anger, outbursts, blaming others, or frustration. The other primary symptom is loss of interest or pleasure in usual activities. Loss of interest or pleasure is almost always present to some degree in individuals with depression (Enneking et al., 2019). An individual experiencing social anhedonia may report feeling less interested in hobbies, "not caring anymore," or not feeling enjoyment in activities that were previously considered pleasurable. The individual is often socially withdrawn and neglects pleasurable activities.

In addition to depressed mood or loss of pleasure, at least four other symptoms are required including changes in weight or appetite, dysregulated sleep, physical agitation or retardation, loss of energy, feelings of worthlessness or excessive guilt, impaired concentration, and suicidal ideation (APA, 2013). The appetite change involves either a reduction or increase in eating. Depending on the appetite change, the individual may gain or lose a significant amount of weight. The sleep disturbances may involve either difficulty sleeping or sleeping excessively. Sleep disturbances are shown by waking up during the night, not being able to return to sleep, waking up too early, difficulty falling asleep, or an increase in daytime sleep. Psychomotor agitation involves inability to sit still, pacing, playing or fidgeting with skin, clothing, or other objects, whereas retardation is shown with slowed speech, thinking, and body movements. Speech is altered in volume, inflection, amount, variety of content, and/or muteness. Psychomotor agitation and retardation are observable by others. A person with depression may also experience loss of energy or fatigue (e.g., decreased energy and tiredness). Physical exertion is not required to have feelings of fatigue; a small task can cause an excess amount of effort or 
energy. Everyday tasks may seem twice as difficult as well as take twice the amount of time. Feelings of worthlessness or guilt are common among depressed individuals as well. A depressed individual may express unrealistic negative evaluations of one's worth and feel excessive guilt over minor mistakes. The individual's feelings of worthlessness and guilt are sometimes delusional and exaggerated (e.g., an individual is convinced they caused a person to die when in reality they died of cancer) (APA, 2013). Impaired concentration is also common. Subramaniapillai et al. (2019) reported that common deficits during depressive episodes of depression are motivation, reward, and cognition. They found a positive association between depressive symptoms and overall cognitive measures. Individuals report impaired ability to think, concentrate, and make minor decisions. Additionally, depressed individuals are easily distracted and experience memory difficulties. An example of deficits in cognition is quality of schoolwork or work decreasing. Lastly, suicidal ideation, thoughts of death, or suicide attempts are common among depressed individuals. These individuals tend to feel hopeless and a need to end their painful emotional state (APA). Among 368 chronically depressed individuals, 75 participants (19.4\%) reported previous suicide attempts (Ernst et al., 2019).

To meet criteria for an MDE, these symptoms cause clinically significant distress or impairment in social, occupational, or other important areas of functioning (APA, 2013). Impairment may range from mild to complete incapacity. Complete incapacity may involve an individual being unable to attend to basic self-care needs, becoming mute, or becoming catatonic. Another impairment is becoming so socially withdrawn that the individual feels completely alone. Additionally, other individuals may withdraw from the depressed individual due to feeling that there is nothing they can do for the individual. The cognitive deficits an individual experiences may lead to a variety of impairments in other areas of the individual's 
life. For example, the individual may feel inadequate to communicate with others, their grades may drop at school, or they may not meet deadlines at work. When an individual is severely depressed, they may become desensitized to emotions due to feeling such intense emotion with the severely depressive episode (Rottenberg 2005, 2007).

In addition to the experience of these symptoms and problems with impairment, depression is related to one's experience of affect. Bylsma et al. (2011) studied individuals with MDD and minor depression. (Minor and subthreshold depression are common conditions. Patients falling below the diagnostic threshold experience significant difficulties in functioning and a negative impact on their quality of life [Rodrigues et al., 2012].) Individuals with MDD and minor depression, compared to healthy controls, reported greater daily negative affect, reported lower positive affect, and reported events as less pleasant, more unpleasant, and more stressful. Both mood-disordered groups reported greater reductions in negative affect following positive events than healthy controls. Furthermore, individuals with depression also experience deficits in their emotional disclosure.

\section{Emotional Disclosure}

Social sharing of emotion occurs in the conversations in which individuals openly communicate about the emotional circumstances of an event and about their own feelings and reactions (Rimé, 2009). Another term for social sharing is emotional disclosure. Emotional disclosure is the process of talking about personal, emotional material with others (Kahn \& Garrison, 2009). An example of emotional disclosure is if an individual is experiencing suicidal ideations and hopelessness due to an intense feeling of sadness, the individual would then express in writing or verbally to another person their thoughts and feelings of their depressed mood. 
Research indicates that emotional disclosure leads to many benefits in individuals. Expressing feelings and thoughts about stressful or traumatic events is helpful for an individual's physical and psychological health (Pennebaker \& Seagal, 1999). For example, research indicates that individuals who disclosed emotions and thoughts about a traumatic event had fewer health center visits at 6-month follow-up than those who did not disclose (Acar \& Dirik, 2019). Severity of symptoms in individuals with rheumatoid arthritis is negatively associated with emotional disclosure (Kelly et al., 1997). Emotional disclosure also leads to improved liver function and a better immune system (Esterling et al., 1994; Francis \& Pennebaker, 1992; Pennebaker et al., 1988; Petrie et al.,1995).

In regard to psychological health, emotional disclosure has been associated with a decrease in symptoms of psychological distress (Cutts, 2018). According to Opre et al. (2005), psychological distress represents symptoms or attitudes specific to a disorder, whereas physical and mental health represented general health. According to the American Addiction Center (2020), distress is negative stress and causes anxiety and concern, is perceived as outside of one's coping abilities, feels unpleasant, and can lead to mental and physical problems. Examples of things that may cause distress include death, divorce, hospitalizations, illness, abuse, conflict in interpersonal relationships, money problems, unemployment, sleep disturbances, legal problems, etc. (American Addiction Center, 2020). With respect to emotional disclosure, Opre et al. (2005) focused on emotional distress in students' college life and found that participants benefit from disclosing by reducing psychological distress and by improving physical and mental health. Further, college women with a history of sexual assault reported reductions in negative mood after disclosing their most severe victimization (Kearns et al., 2010). Similarly, when examining individuals who have experienced traumatic life events, disclosing not only reduced 
psychological distress but changed self-perception, resulting in an increase in resilient selfconcept (Hemenover, 2003). Research has also shown emotional disclosure helps improve cognitive processing and distress in couples coping with head and neck cancer (Bakhshair et al, 2020).

Individuals differ in their tendencies to disclose psychological distress. Although who a person is determines whether there is social sharing, an event can also determine whether there is social sharing. Rimé's $(1995,2009)$ theory of social sharing implies that individuals are more likely to share their emotions with others when they have experienced a distressing event. The fever model of disclosure (Stiles, 1987, 1995) supports Rimé's theory and suggests that the more distressed an individual is, the more he or she will disclose about the distress. The nature of the emotion an individual is disclosing can also dictate whether the individual is more or less likely to disclose. For example, research indicates an individual is more likely to self-disclose an anxiety-provoking event compared to a happy event (Stiles et al., 1992).

\section{Depression and Emotion Disclosure}

One could make the connection that individuals with emotional disorders disclose more than individuals without disorders due to Rimé's theory and the fever model (Rimé, 1995, 2009; Stiles, 1987, 1995). However, research has also shown an association between depression symptoms and willingness to talk about one's distress. Garrison and Kahn's (2010) research indicates that individuals with high levels of depression are less likely to engage in emotional disclosure than individuals who are lower in depressive symptoms. Other research has shown that emotional self-disclosure is diminished among those with symptoms of depression (Barr et al., 2008; Kahn \& Garrison, 2009; Kahn \& Hessling, 2001; Rude \& McCarthy, 2003). For example, research indicates college students who reported mild depression were less likely to 
engage in emotional disclosure than nondepressed college students (Rude \& McCarthy, 2003). Additionally, it has been found that symptoms of depression predict a decrease in the likelihood of disclosing distress over a 2-month period (Kahn \& Hessling, 2001).

One potential reason for this negative depression-disclosure relation comes from the emotion dysregulation theory of depression (Campbell-Sills \& Barlow, 2007). Individuals with mood and/or anxiety disorders avoid their emotions, have difficulty processing emotions, and view emotions as less acceptable which leads to a decrease in emotional disclosure (Baker et al., 2005; Campbell-Sills et al., 2006; Kahn \& Garrison, 2009). Kahn and Garrison (2009) explain that because individuals with mood and anxiety disorders avoid the experience and expression of negative emotions, they therefore talk less about negative emotions with others. As noted, research shows that expressing feelings and thoughts about stressful or traumatic events is helpful for physical and mental health, cognitive processing, and distress (Acar \& Dirik, 2019; Bakhshair et al., 2020). Individuals with depression symptoms may therefore experience increased negative affect due to their tendency to disclose less than an individual without depression symptoms.

This association between depression symptoms and emotional disclosure can be explained by perceptions of the acceptability of emotions among people with elevated depression symptoms. Campbell-Sills et al. (2006) studied perceived acceptability and suppression of negative emotion in participants with anxiety and mood disorders. The study involved 60 participants with mood disorders (clinical group) and 30 control participants with no clinical history (non-clinical group). Participants were asked to watch an emotion-provoking film and complete self-report measures of their experience and regulation of emotions. Campbell-Sills et al.'s findings indicated individuals with anxiety and mood disorders differ from control 
participants in their tendency to suppress emotions and judge emotions as unacceptable. In fact, when individuals watched the same emotion-provoking film, individuals with anxiety and mood disorders exhibited greater use of suppression, but not other emotion regulation skills. This difference was attributable to increased suppression by females with disorders compared to females without these disorders. Further, clinical participants judged their emotions from the film as less acceptable than non-clinical participants (Campbell-Sills et al., 2006). Additionally, the belief that emotions were unacceptable mediated the relationship between intensity of negative emotions and if an individual suppressed their emotions. In other words, judging emotions as unacceptable was functionally related to suppression in the clinical sample in that intensity of negative emotion predicted unacceptability of emotions which in turn predicted suppression.

A second possible explanation for the association between depression symptoms and emotional disclosure concerns the perception of the intensity of a negative event. On the one hand, individuals with depression are more likely to rate the intensity of negative events as higher than non-depressed individuals (Garrison \& Kahn, 2010). This research suggests that individuals with higher levels of depressive symptoms experience more stressful life events than individuals without depressive symptoms (Kessler, 1997). However, Rottenberg $(2005,2007)$ found that individuals with depressive symptoms may experience negative emotions at a lower level of intensity than do individuals without depressive symptoms due to individuals with depression becoming desensitized to distressing events. Although research suggests individuals with depressive symptoms experience more negative events than individuals without depression, according to Rottenberg, a person with depressive symptoms will likely experience less arousal to distressing events which might result in little expression of whatever emotions do result from the event (Rottenberg, 2005, 2007). Rottenberg's research indicates that individuals with 
depression experience excessive negative moods over time which results in emotion-context insensitivity.

Emotion context insensitivity (ECI) in major depressive disorder was researched by Rottenberg et al. (2005). According to the ECI hypothesis, depressed individuals should not respond to emotions typically when put into a various emotional context (e.g., happy, sad, or neutral states). To test the ECI hypothesis, Rottenberg et al. used a group of currently depressed individuals, formerly depressed individuals, and healthy controls who had never been depressed and measured their self-reported experiential, behavioral, and autonomic responses after eliciting happy, neutral, or sad states with a short film. Currently depressed individuals reported less sadness reactivity and less happiness experience across all conditions than did other participants, suggesting depression may produce mood-state-dependent changes (decreased negative emotion) in emotional reactivity (Rottenberg et al., 2005).

\section{The Present Study}

The first aim of the present study was to examine the relationship between depression and emotional disclosure. Research suggests depression is negatively associated with emotional disclosure (Barr et al., 2008; Garrison \& Kahn, 2010; Kahn \& Garrison, 2009; Kahn \& Hessling, 2001; Rude \& McCarthy, 2003). Findings also suggest the relationship between these two variables is more complex than meets the eye. In fact, various factors may account for the relationship between depression and emotional disclosure. An individual with depression may therefore choose not to engage in emotional disclosure for many reasons. The present study investigated those factors. For starters, individuals with depression experience excessive negative mood which results in emotion-context desensitivity. An individual who does not experience emotional arousal from a situation will not feel the need to disclose. Therefore, an individual 
with depression experiencing emotion-context desensitivity will not emotionally disclose due to desensitization of emotions (i.e., experience of low emotional intensity) caused by event.

Further, individuals with depression view emotions as less acceptable than individuals without depression (Campbell-Sills et al., 2006). An individual is not likely to disclose emotions they view as unacceptable. Therefore, an individual with depression will not engage in emotional disclosure due to viewing emotions as unacceptable.

Based on previous findings, the first hypothesis was that depressive symptoms would be negatively associated with emotional disclosure. The second hypothesis was individuals reporting more depression symptoms would experience less subjective intensity of emotion in response to a real-life, unpleasant event. The third hypothesis was individuals reporting more depression symptoms would view emotions concerning the negative event as less acceptable. The fourth hypothesis was the negative relationship between depression symptoms and emotional disclosure would be mediated by (a) acceptability of emotions and (b) emotional intensity (see Figure 1). To test these hypotheses, a parallel multiple mediation model was used. 


\section{Figure 1}

The Parallel Multiple Mediation Model Expected in the Study

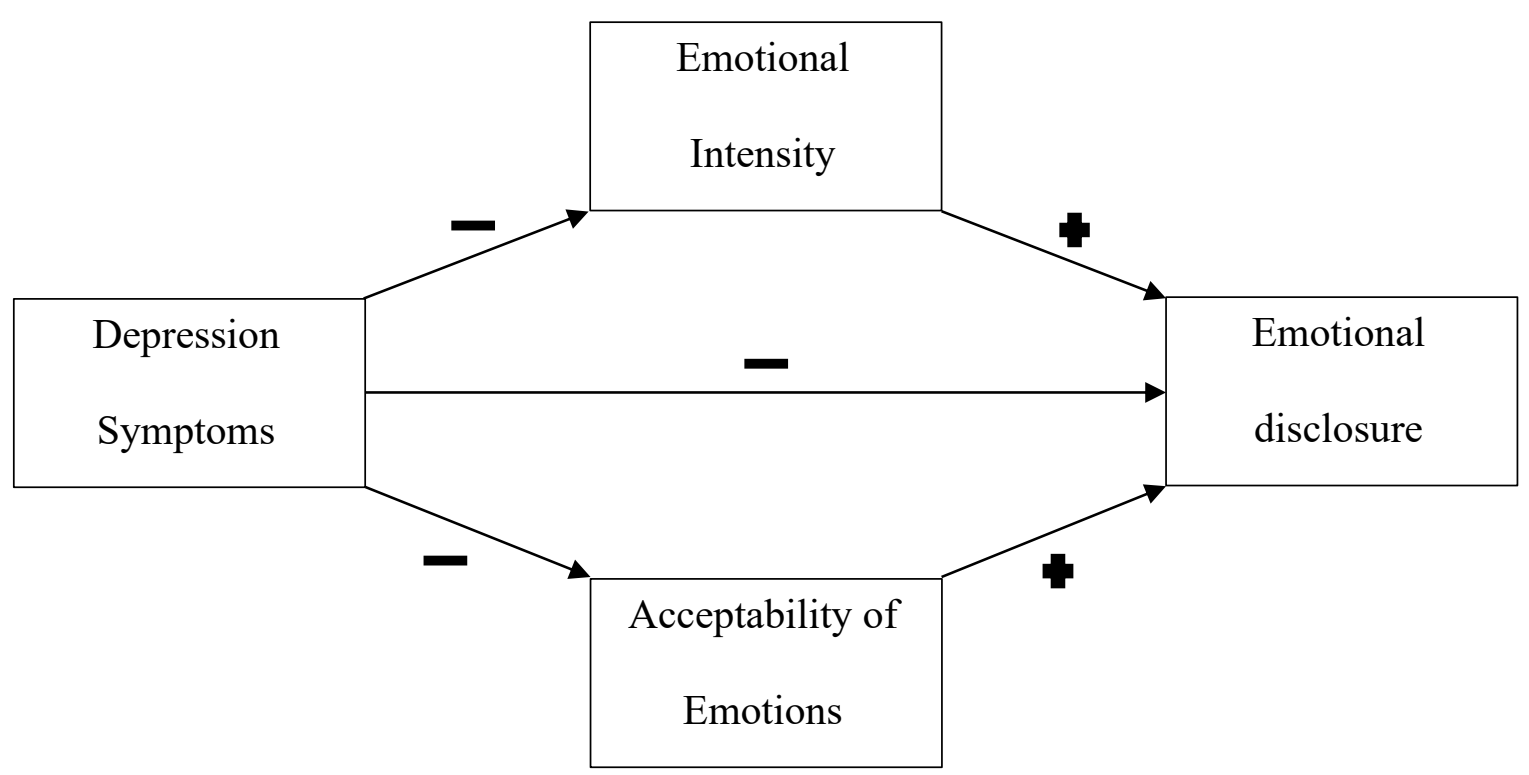




\section{CHAPTER II: METHOD}

\section{Participants}

Participants were college students recruited from the Department of Psychology participant pool. There were 234 participants, 10 of which were excluded from the original 244 sample size due to providing no consent, leaving all items unanswered, leaving all intensity items unanswered, omitting an acceptability item, or not disclosing a sad event. Participants were aged 19 to 55 years $(M=20.42, S D=4.31)$. The sample included, 207 females, 24 males, and 3 other (trans, fluid, etc.). The demographics of the participants were similar to the university population: over half (62\%) identified as Caucasian/European American followed by 12\% Latino or Latina, 12\% African American, 4\% other race/ethnicity/cultural background, 3\% Asian American or of Asian descent, 3\% Biracial or multiracial, 3\% Middle Eastern descent, and 1\% Native American/American Indian. Lastly, participants included 72 first-year students, 70 sophomores, 57 juniors, 30 seniors, and 5 graduate students.

\section{Measures}

\section{Depression Symptoms}

Depression was measured using the 9-item Patient Health Questionnaire (PHQ-9; Spitzer et al., 2001). Participants were given 9 questions to measure the severity of their depression: minimal depression, mild depression, moderate depression, moderately severe depression, and severe depression. Participants were asked to indicate over the last 2 weeks how often they have been bothered by depressive symptoms using a 4-point Likert scale from 0 (Not at all) to 3 (Nearly every day), such that higher scores reflect more severe depression. In terms of reliability of the PHQ-9, Cronbach's coefficient alpha ranged from .86 to .89 (Kroenke et al., 2001). In the current study, Cronbach's coefficient alpha was .87. 


\section{Disclosure of Real-Life Event}

Recall of Sad Event. Participants were instructed to write about a time when they felt sad in the past month. Additionally, participants were asked to describe and explain the personal experience in as much detail as possible. On average, participants wrote about 123 words, with a minimum of 14 and a maximum of 685 . The thesis chair and author generated a list of categories from independently reading 50 entries each from current study. After discussion, the list of categories included: primary support group (e.g., relationship conflict/breakup/concern, etc.), Social environment (e.g., social relationships/loneliness/isolation/homesickness, etc.), Educational problems (e.g., school challenges, etc.), Economic/occupational (e.g., work problems, money concerns, etc.), Loss/death (e.g., Human, pet), Physical health, Mental health (e.g., crying, no motivation, stress, generalized distress, feeling hopeless, low self-esteem, etc.), Other psychosocial/environmental problems, insufficient information, and COVID-related (e.g., health, lockdown, remote learning, unemployment, etc.; yes or no). From this list, three external raters were asked to identify the topic of given event. Categories of events based on raters were primary support group (16-17\%), social environment (17\%), loss/death (17\%), educational problems (14-16\%), mental health (11-15\%), economic/occupational (3-5\%), and physical health (4-8\%). The remaining events were identified as other psychosocial/environmental problems (5-10\%) or insufficient information (2\%). About 20\% of events included COVID-19.

Intensity of Sad Event. After disclosing the sad event, participants were presented with three questions from Garrison et al.'s (2012) study on depression symptoms and adult attachment on emotional disclosure. The questions measure the degree to which the event was intense and negative according to the participant: "How intense was your emotional reaction to the unpleasant event?," "How negative were your feelings about the unpleasant event?," and "How 
much sadness did you experience?" The questions were rated on a 5-point scale ranging from 1 (very slightly or not at all) to 5 (extremely). In terms of reliability and efficiency of the Garrison et al. scale, Cronbach's coefficient alpha was .86. In the current study, Cronbach's coefficient alpha was .88 .

Three external raters were also used to rate the intensity of the event described. External raters independently read the description of the sad event and rated them based on comparing each event to every other event. External raters were asked to not infer what the participant felt but rather try to rate the intensity more objectively. Overall intensity was rated using the following items: "How intense was the unpleasant event?," "How negative was the unpleasant event?," and "How much sadness would this experience bring (to an average person)?" The questions were rated on the same 5-point scale from Garrison et al.'s (2012) study. The intraclass correlation coefficient for the three external raters for intensity, negativity, and sadness items were as follows: $.76, .72$, and .67 . Item ratings for the three raters were averaged, and then they were summed to generate a total intensity score from the raters. A difference score was then created to measure participants' emotional intensity above what is expected (positive numbers) or below what's expected (negative numbers). The difference score was created by subtracting the external raters' rating from the participant's rating.

\section{Acceptability of Emotion}

Meta Evaluation Scales (MES; Mayer \& Stevens, 1994). Attitudes toward emotions was measured on the MES. The 6-item acceptability subscale of the MES was used in the current study to measure how acceptable participants viewed their emotions concerning the sad event they described from the past month. The acceptability subscale (MES-A) asked participants to review their mood and describe their thoughts and feelings about their mood and its influence on 
them. Items are rated on a 5-point scale ranging from 1 (definitely does not describe my mood) to 5 (definitely describes my mood). Higher scores indicating more acceptance of emotions.

Analyses by the scale authors suggest that the MES is a reliable and valid instrument (Mayer \& Stevens, 1994). Mayer \& Stevens (1994) completed two studies in which the coefficient alpha reliabilities of the acceptability subscale were .75 and .78 . In study one the acceptability subscale was significantly correlated with the clarity (.21), typicality (.17), influence (-.25), repairing ($.23)$, and maintenance (.56) subscales. In study two the acceptability subscale was significantly correlated with clarity (.47), typicality (.38), influence (-.27), repairing (-.23), and maintenance (.54) subscales. Further, study two found the acceptance subscale was correlated with the Alexithymia subscales measuring the ability to identify present emotional experience $(.32)$ and to describe those emotional expriences (.32). Accetance of mood was also moderately associated with fewer borderline characteristics (-.43) and negatively with wishful thinking (-.30) and selfblame (-.32). In the current study, Cronbach's coefficient alpha was .78.

\section{Emotional Disclosure}

Emotional disclosure of the sad event from the past month was assessed with three items from Garrison and Kahn's (2010) study which focuses on degree of sharing and talking about unpleasant events with others. The three items included: "To what degree have you shared information about this unpleasant event with someone (i.e., by talking with someone, texting someone, posting an online message, etc.)?," "How much did you share your thoughts about the unpleasant event?," and "How much did you share your feelings about the unpleasant event?" These items were measured on the same 5-point scale as the intensity items $(1=$ Very slightly or not at all to $5=$ Extremely). In terms of reliability of the Garrison and Kahn scale, Cronbach's coefficient alpha was .94. In the current study, Cronbach's coefficient alpha was .92. 


\section{Procedure}

The sample was students in a psychology course that were able to sign up for studies, by SONA (a research participation system), in exchange for extra credit. This study was approved by the Institutional Review Board. The study was completed online by all participants though Qualtrics, an online survey software program, and could be taken on any computer, phone, or tablet at any location. Respondents began the online survey by reading through the informed consent form and were given the option to either continue or end the survey. Participants who agreed to continue with the study were given the first task, the 9-item PHQ-9, where they were asked how often they have been bothered by items related to depression.

Participants were asked to recall a sad event and describe the unpleasant personal experience. Instructions included, "On this page, please type about a time in the past month when you felt sad. You may write about any time in the past month or any event, but it is important that you write about a time when you felt sad or unhappy. Write as much as you can about this time and what it was like." Participants indicated the intensity of the event with questions from Garrison et al. (2012). Next, participants took the MES acceptability subscale to measure acceptability of emotions. Participants then completed three items adapted from Garrison and Kahn's (2012) to measure disclosure. To conclude the study, participants were asked to answer several demographic questions including age, educational level, ethnicity, and gender. Participants were awarded course credit for completing survey. Participants were given a debriefing page where they could learn more about the study.

After all data were collected external raters coded each unpleasant event's intensity using the items described above. Three external raters participated in training and coding for 5 weeks. First, they were given a set of sample events from a previous study on unpleasant events on 
which to practice their ratings. The three external raters and thesis chair discussed external raters' results to the sample events. The thesis chair, Dr. Jeffrey Kahn, and thesis author, Brandie Vera, met to discuss external raters' questions and discrepancies. At this time, the questions for the three coders to rate intensity, negativity, and sadness were finalized. After finalizing these items, the three raters were given the open-ended responses from the first 60 participants. Raters were blind to all other data including participants' self-reports. Ratings were discussed in a group, and then the next 60 participants' data were given to raters. Another meeting was held to discuss, in depth, ratings that had large disagreements. The next 60 participants' unpleasant events were coded with revisions and previous discussion in mind. During the last week, the final group of participants' data were rated.

\section{Data Analysis Plan}

Data analyses were performed using SPSS. First, descriptive statistics for gender, age, and education level were analyzed to describe the sample. My hypothesis was tested using parallel mediation analysis. This analysis assessed the extent the variables predict one another. Further, it assessed which of the mediators (M; acceptability of emotions \& emotional intensity) explains the relationship between the independent variable (X; depression symptoms) and the outcome variable ( $\mathrm{Y}$; emotional disclosure). This analysis also assessed direct and indirect effects of the variables. The criterion for statistical significance was $p<.05$. 


\section{CHAPTER III: RESULTS}

\section{Preliminary Findings}

It was hypothesized that individuals with higher depression scores would have lower emotional disclosure scores compared to those who had depression scores. A series of Pearson correlations were computed to test this prediction (see Table 1). In regard to the present study's

hypotheses, individuals' depression scores and their reports of disclosure of the sad event were not significantly correlated. On the other hand, participants with higher intensity scores had significantly higher depression and disclosure scores. Further, participants' intensity score were significantly correlated with external raters' intensity scores and the intensity difference scores. External raters' intensity scores were significantly correlated with the intensity difference score. The intensity difference score was significantly correlated with depression symptoms and acceptability of emotions. Finally, individuals with higher depression scores had significantly lower acceptability of emotions scores. 


\section{Table 1}

Reports of Scales: Correlations and Descriptive Statistics $(N=234)$

\begin{tabular}{|c|c|c|c|c|c|c|}
\hline Variables & 1 & 2 & 3 & 4 & 5 & 6 \\
\hline 1.Depression & - & & & & & \\
\hline 2. Intensity (participants) & $.32 * * *$ & - & & & & \\
\hline 3.Intensity (external) & .09 & $.38 * * *$ & - & & & \\
\hline 4. Intensity (difference) & $.21 * *$ & $.57 * * *$ & $-.54 * * *$ & - & & \\
\hline 5. Acceptability of emotion & $-.25 * *$ & -.09 & .07 & $-.14 *$ & - & \\
\hline 6. Disclosure & -.06 & $.23 * *$ & .10 & .12 & .10 & - \\
\hline$M$ & 10.05 & 11.65 & 9.12 & 2.54 & 19.40 & 8.94 \\
\hline$S D$ & 5.82 & 2.75 & 2.69 & 3.03 & 5.74 & 3.55 \\
\hline$\alpha$ & .87 & .88 & .71 & - & .78 & .92 \\
\hline Possible range & $0-27$ & $3-15$ & $3-15$ & $-12-12$ & $6-30$ & $3-15$ \\
\hline Observed range & $0-26$ & $3-15$ & $3-15$ & $-9-10$ & $6-30$ & $3-15$ \\
\hline
\end{tabular}


Further analysis was done on participants disclosure of real-life event. On average participants wrote about 123 words. The disclosure of real-life event with the lowest word count consisted of 14 words and the disclosure with the highest word count consisted of 685 words. According to external raters the most common topic of disclosure of real-life event was social environment (18\%) and the least common topic was physical health (6\%). External raters also identified $17 \%$ of events included COVID-19.

In regard to the Patient Health Questionnaire (PHQ-9), the possible range of scores is 027, whereas the observed range of scores was 0-26. Participants scores were interpreted as minimal depression $(1-4, n=51)$, mild depression $(5-9, n=63)$, moderate depression $(10-14, n=$ $61)$, moderately severe depression $(15-19, n=44)$, and severe depression $(20-26, n=15)$. The PHQ-9 recommends to consider Major Depressive Disorder if at least 5 or more questions (one of which corresponds to question \#1 or \#2) are answered "more than half the days" or "nearly every day" which includes of 69 participants. Further, the questionnaire recommends to consider other depressive disorder if there are 2-4 questions (one of which corresponds to question \#1 or question \#2) answered "more than half the days" or "nearly every day" which includes 18 participants.

\section{Main Analysis}

The main hypothesis was that emotional intensity and acceptability of emotion would mediate the relationship between depression symptoms and emotional disclosure. A parallel mediation analysis was conducted to determine if depression and emotional disclosure were mediated by emotional intensity and acceptability of emotion. Using the PROCESS macro Model 4 (Hayes, 2017), the Patient Health Questionnaire (PHQ-9) was used as the X variable, 
participants' emotional intensity was M1 variable, acceptability of emotions was the M2 variable, and emotional disclosure was the $\mathrm{Y}$ variable.

\section{Participant Self-Reports of Intensity}

The first model included emotional intensity from participant self-reports. The slope for depression symptoms predicting emotional disclosure was non-significant, $b=-.07, p=.08$ (see Figure 2). Next, a significant effect of depression symptoms on emotional intensity from selfreports was found, $b=.15, p<.0001$, with individuals with higher depression scores showing higher ratings of intensity. Further, a significant effect of depression symptoms on acceptability of emotions was found, $b=-.25, p=.0001$, with individuals with higher depression scores showing lower acceptability of emotions. Emotional intensity was a significant positive predictor of disclosure, $b=.36, p<.0001$. Finally, acceptability of emotions was not a significant predictor of disclosure, $b=.06, p=.15$. 


\section{Figure 2}

The Parallel Multiple Mediation Model with Emotional Intensity Self-Reports

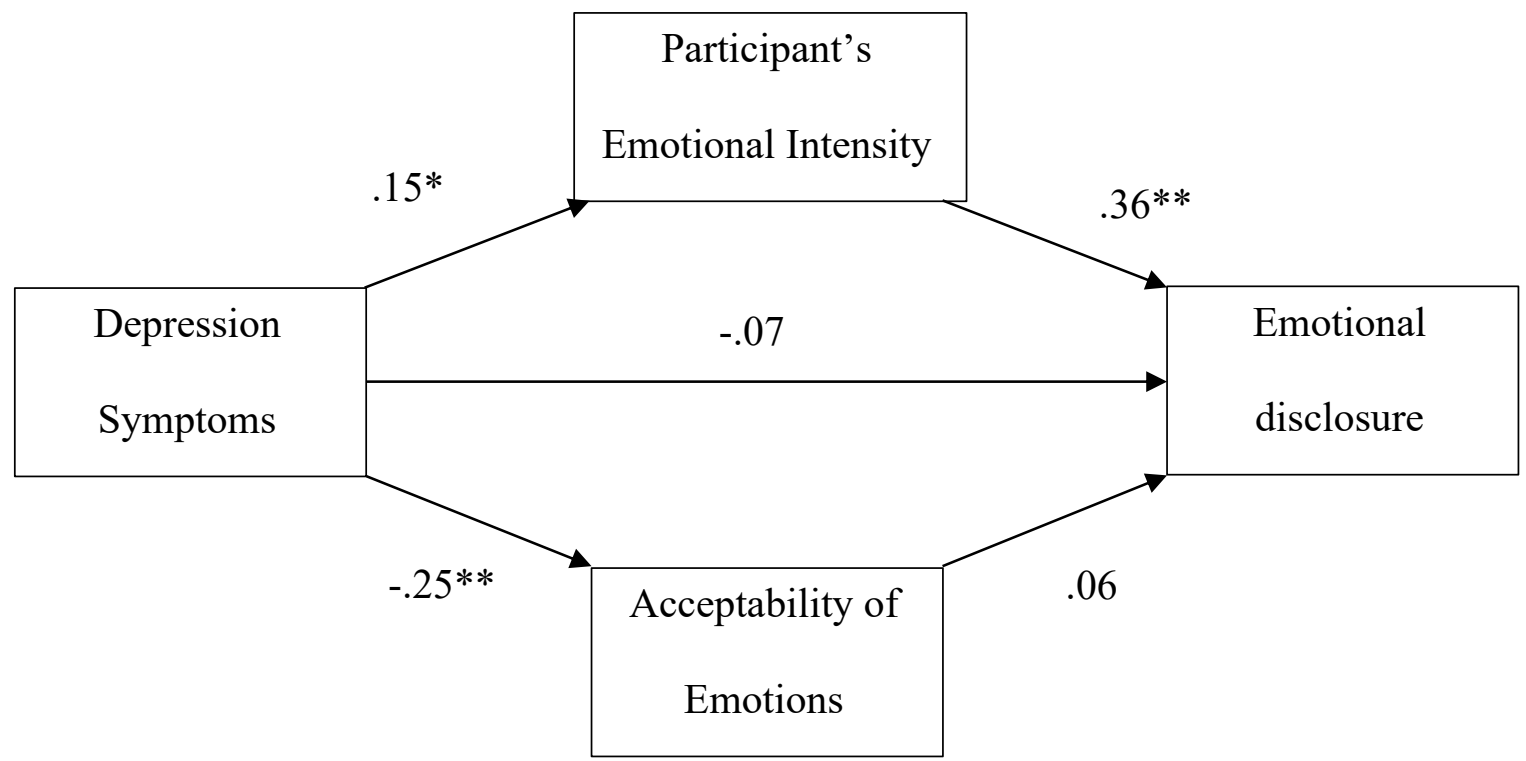

$* p<.05 . * * p<.01 . * * p<.001$.

The indirect effect of depression symptoms on emotional disclosure via emotional intensity self-reports (.05) was positive and statistically significant: $95 \%$ confidence interval (CI) $=(.02, .09)$. The indirect effect of depression symptoms on emotional disclosure via acceptability of emotions (-.01) was non-significant: $95 \%$ confidence interval $(\mathrm{CI})=(-.04, .01)$. Acceptability of emotions did not mediate the relationship between depression and emotional disclosure. Participants' subjective intensity of emotion did mediate the relationship between depression symptoms and emotional disclosure.

\section{Intensity Difference Scores}

Another parallel mediation analysis was conducted to determine if emotional intensity and acceptability of emotions mediated the relationship between depression and emotional disclosure; however, this time I used the intensity difference score. The difference score was 
created by subtracting the external raters' rating from the participant's rating. The difference score was created to measure emotional intensity above what is expected (positive numbers) or below what's expected (negative numbers). Other than substituting the self-report intensity score with the self-rater difference score, the model was identical to the one above (see Figure 3 ). Although the slope for depression symptoms predicting emotional disclosure was negative, it was not statistically significant, $b=-.04, p=.38$. Next, a significant effect of depression symptoms on the difference score of emotional intensity was found, $b=.11, p=.001$, with individuals with higher depression scores showing higher difference scores for emotional intensity. Additionally, a significant effect of depression symptoms on acceptability of emotions was found, $b=-.25, p=.0001$. The difference score of emotional intensity was a significant positive predictor of disclosure $b=.17, p=.03$, but acceptability of emotions was not a significant predictor of disclosure $b=.07, p=.12$.

\section{Figure 3}

The Parallel Multiple Mediation Model with Emotional-Intensity Difference Scores

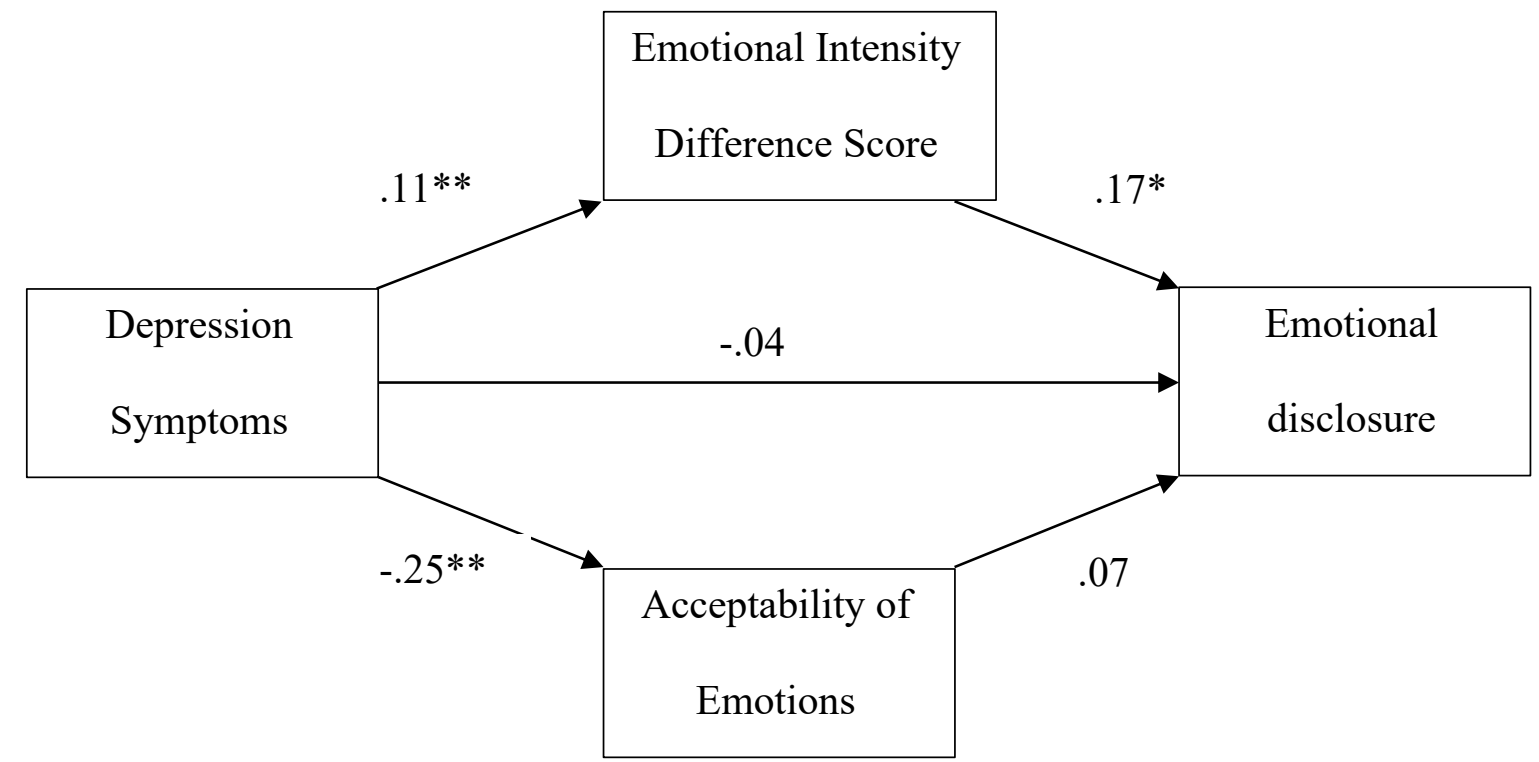

$* p<.05 . * * p<.01 . * * p<.001$. 
The indirect effect of depression symptoms on emotional disclosure via difference score of emotional intensity (.02) was positive and statistically significant: 95\% confidence interval $(\mathrm{CI})=(.001, .04)$. The indirect effect of $\mathrm{X}$ on $\mathrm{Y}$ via acceptability of emotions (-.02) was nonsignificant: $95 \%$ confidence interval $(\mathrm{CI})=(-.04, .01)$. Emotional intensity mediated the relationship between depression symptoms and emotional disclosure when using the intensity difference score, but acceptability of emotions did not mediate that relationship.

\section{The Role of Gender}

The same two parallel mediation analyses were conducted again to determine if emotional intensity and acceptability of emotions mediated the relationship between depression and emotional disclosure; however, this time the analyses were done with gender as a covariate. Gender ( 1 = Woman, 2 = Man, 3 = Other) was used as a control. Select Cases in SPSS (gender $<$ 3) was utilized to analyze data for people identifying as women (coded 1) or men (coded 2). Select Cases allowed me to exclude the 3 individuals who identified as other and only include women and men in analysis. Due to the limited number of individuals who identified as other

(coded 3), it was difficult to include and analyze the 3 individuals who identified as other. Other than using gender as a control, the model was identical to the two above.

Gender as a control did not alter results significantly. In regard to the first model which included emotional intensity from participant self-reports, all results remained the same with the exception of the slope for depression symptoms on emotional disclosure. The slope for depression symptoms predicting emotional disclosure with gender as a control was a negative relationship, $b=-.09, p=03$, and significant, whereas it was non-significant in model 1 . 


\section{Table 2}

Report of Slopes: Coefficients and Standard Error

\section{Outcome Variables}

\begin{tabular}{cccc}
\cline { 2 - 4 } Predictor Variables & Intensity & Acceptability & Disclosure \\
\hline Depression & $.15(.03)$ & $-.25(.06)$ & $-.07(.04)$ \\
Intensity (participants) & & $.36(.09)$ \\
Acceptability & & $.06(.04)$
\end{tabular}

Table 3

Report of Slopes: Coefficients and Standard Error

\section{Outcome Variables}

\begin{tabular}{cccc} 
Predictor Variables & Intensity & Acceptability & Disclosure \\
\hline Depression & $.11(.03)$ & $-.25(.06)$ & $-.04(.04)$ \\
Intensity (difference score) & & $.17(.08)$ \\
Acceptability & & $.07(.04)$ \\
\hline
\end{tabular}


Table 4

Report of Slopes with Gender as Covariate: Coefficients and Standard Error

$$
\text { Outcome Variables }
$$

\begin{tabular}{cccc} 
Predictor Variables & Intensity & Acceptability & Disclosure \\
\hline Depression & $.15(.03)$ & $-.25(.06)$ & $-.09(.04)$ \\
Intensity (Participants) & & $.34(.09)$ \\
Acceptability & & $.05(.04)$ \\
\hline
\end{tabular}

Table 5

Report of Slopes with Gender as Covariate: Coefficients and Standard Error

Outcome Variables

\begin{tabular}{cccc} 
Predictor Variables & Intensity & Acceptability & Disclosure \\
\cline { 2 - 3 } & $.11(.03)$ & $-.25(.06)$ & $-.06(.04)$ \\
Depression & & $.17(.08)$ \\
Antensity (difference score) & & $.06(.04)$ \\
\hline
\end{tabular}




\section{CHAPTER IV: DISCUSSION}

The purpose of the current study was to investigate if emotional intensity and acceptability of emotions mediate the relationship between depression and emotional disclosure. In order to investigate the topics, the PHQ-9 was used to measure depression, three questions from Garrison et al. (2012) were used to measure intensity of a recent sad event, the MES-A was used to measure acceptability of emotion, and three items from Garrison and Kahn's (2010) study were used to measure emotional disclosure.

Although I expected a negative relationship between depression symptoms and emotional disclosure, there was no significant relationship. In other words, my first hypothesis was not supported. However, a variety of research supports the association between depression symptoms and willingness to talk about one's distress (Barr et al., 2008; Garrison \& Kahn, 2010; Kahn \& Garrison, 2009; Kahn \& Hessling, 2001; Rude \& McCarthy, 2003). One possibility for the current finding is the time period in which the study took place. Collection of data took place during COVID-19 which influenced individuals' circumstances. For starters, individuals were adjusting to new forms of communication. Further, the most common categories of events reported based on raters were primary support group (16-17\%) and social environment (17\%) suggesting participants were experiencing isolation and lack of support. Individuals were forced into isolation making it more difficult to emotionally disclose. Further, participants were taken away from their support system by having to move home (away from friends) and/or not go home for holidays (away from family). Additionally, research implies many individuals with depression perceive lessened social support (Sacco, 1999) and tend to withdraw from interpersonal relationships (Coyne \& Calarco, 1995); therefore, emotional disclosure is diminished. 
It is important to note there was a significant relationship between depression symptoms and emotional disclosure when controlling for gender binary. The assumption can be made that males and females with depression symptoms differ in their tendencies to emotionally disclose. Sultan and Hima (2008) report significant gender difference in emotional self-disclosure, where women disclosed their emotions more to their friends as compared to men. Their study further found that there are differential tendencies among male and female students in disclosing their different types of emotions to male and female recipents. Further investigation is needed in regard to gender on the relationship between depression symptoms and emotional disclosure, particularly with a more representative sample.

Another factor that may have influenced results is the characteristics of the sample. Specifically, participants were recruited from Illinois State University's psychology participant pool; thus, all of the sample consisted of college students enrolled in a psychology course. Further, universities have been making efforts to increase awareness on mental health and encouraging students to seek help altering college students attitudes regarding mental health. For example, Bourne (2021) found that strategies aimed at improving mental health awareness and increaking the help-seeking behaviors of the university students made a statistically significant difference in the mental health perception of students. Therefore, the assumption can be made that participants in the current study may be more aware of depression symptoms, more accepting of emotions, and more willing to emotionally disclose compared to non-college students.

Next, I expected depression symptoms and emotional intensity to have a negative relationship; however, individuals reporting more depression symptoms experienced more emotional intensity in response to real-life, unpleasant event. Rottenberg et al. (2005) finds 
individuals with higher levels of depression symptoms experience negative emotions at a lower level of intensity than individuals without due to becoming desensitized to distressing event. Conversely, the current study supports the research which indicates individuals with depression are more likely to rate intensity of negative events as higher than non-depressed individuals (Garrison \& Kahn, 2010). As noted, expressing feelings and thoughts about stressful or traumatic events is helpful for physical and mental health, cognitive processing, and distress. Therefore, depressed individuals may experience increased negative affect due to their tendency to disclose less than an individual without depression symptoms. On the other hand, the assumption could be made that individuals with depression become desensitized to distressing events after experiencing long periods of depression, which is when emotional intensity is rated lower. The current study did not measure how long participants experienced depression symptoms; therefore, participants may have not experienced depression "long enough" to become desensitized. This question merits investigation in future studies. It may be beneficial for this to be investigated with participants who experience persistent depressive disorder.

Third, individuals reporting more depression symptoms viewed emotions concerning the negative event as less acceptable. The current research supports Campbell-Sills et al.'s (2006) findings which indicate individuals with mood disorders differ from control participants in their tendency to judge emotions as unacceptable. These findings are consistent with research that conceptualize maladaptive efforts to control unwanted emotions as part of the phenomenology of emotional disorders (Barlow et al. 2016; Campbell-Sills et al., 2006; Hayes et al., 1999). However, it is important to note that the difference in suppression observed in Campbell-Sills's study was attributable to the behavior of female participants only. In the current study, gender did not influence the results in regard to depression and acceptability of emotion. 
Further, emotional intensity was significantly associated with emotional disclosure. Specifically, individuals who experienced more intensity of emotion were more likely to emotionally disclose. The theory of social sharing (Rimé, 1995, 2009) supports the finding by explaining individuals are more likely to share emotions with others when they experience distress. Additionally, the fever model of disclosure (Stiles, 1987, 1995) supports these findings by explaining the more distressed an individual is, the more he/she will disclose the distress. It is also possible that engaging in emotional disclosure causes an increase in negative emotion, perhaps because the individual is forced to comfront emotions while discussing event.

Acceptability of emotions, on the other hand, did not influence emotional disclosure. The current finding is not supported by Campbell-Sills and colleagues' (2006) research which suggest individuals may suppress their emotions because they appraise them as unacceptable. For example, suppression may be influenced by internal factors, such as enduring beliefs about emotions (e.g., "Showing negative emotions is a sign of weakness") or acute appraisals of emotions (e.g., "This depression is bad, so I should get rid of it," or "Feeling sad right now is wrong"). The assumption can be made that acceptability of emotions is only an important factor when disclosing in persons who have been diagnosed with a mood/anxiety disorder.

Finally, the relationship between depression symptoms and emotional disclosure was mediated by emotional intensity, but it was not mediated by acceptability of emotions. This finding suggests individuals who experience more depressions symptoms experience events that are higher in intensity which makes those events more likely to be disclosed. However, I expected individuals with more depression symptoms to experience events at a lower level of intensity which would make those events less likely to be disclosed. Therefore, the emotioncontext insensitivity and acceptability of emotion hypotheses were not supported. 
Rottenberg's $(2005,2007)$ research found that individuals with depressive symptoms may experience negative emotions at a lower level of intensity than do individuals without depressive symptoms due to individuals with depression becoming desensitized to distressing events. Rottenberg suggested a person with depressive symptoms will likely experience less arousal to distressing events which might result in little expression of whatever emotions do result from the event. Additionally, Rottenberg's research indicates that individuals with depression experience excessive negative moods over time which results in emotion-context insensitivity. The current findings did not support Rottenberg's research.

\section{Limitations and Future Research Directions}

Results should be interpreted with respect to study limitations. One limitation was the use of self-report measures. The current study relied on self-report measures of depression symptoms, emotional intensity, acceptability of emotion, and emotional disclosure; therefore, the

effects of method variance and reporting bias cannot be ruled out. Additionally, participants can only report on emotions and events of which they are conscious. Gross (1999) suggests that emotion regulation behaviors that have become habitual may be acted on without conscious awareness; therefore, participants may have been unaware of emotional disclosures which then impacted their ability to self-report. The issue of retrospective recall is also a potential issue when asking respondents to report something that occurred in the past (Kahn \& Garrison 2009; Reis \& Gable, 2000). The accuracy of participants' reports of emotional intensity, acceptability of emotions, and emotional disclosure is put into question due to retrospective recall. Although self-report measures made it possible to include a large sample of college students, it is important for future work to include interview-based and experimental measures to advance our understanding beyond self-report measures. 
A second potential limitation concerns the sample. Specifically, the sample was not exclusive to participants with Major Depressive Disorder which may have influenced the results. For example, the current study's hypothesis on acceptability of emotion was not supported, whereas Campbell-Sills et al. (2006) focused on individuals with anxiety and mood disorders and found judging emotions as unacceptable was functionally related to suppression in the clinical sample. Future studies should include more methodology to characterize levels and length of depression as well as control groups.

Similarly, a third limitation is the homogeneity of the sample. Over half $(62 \%)$ of the sample identified as Caucasian/European American, and $88 \%$ of the sample identified as a woman. An analysis of cultural differences would have been very informative due to the known cultural differences in expressing emotions and mental health concerns (Guo et al., 2015). Future research examining the generalizability of these findings to non-Caucasian sample is needed. On the other hand, the current study analyzed gender, and gender did not alter findings significantly. Another limitation is this study used a parallel mediation design, which implies a casual chain. The mediator is assumed to be caused by the predictor variable and to cause the outcome variable (Kenny et al., 1998). Therefore, the criteria for establishing causation was considered in study design. With that in mind, it is important future studies use multiple methodologies to strengthen conclusions about the generalizability of the findings. For example, it would be helpful to trace depression symptoms and emotional disclosure using a longitudinal design to better understand the relationships among relevant variables. Similarly, these types of methodologies will allow us to distinguish patterns of emotional disclosure among individuals who are depressed over time. (Frazier et al., 2004; Smith et al., 2019). 
The use of difference scores in the current study should also be acknowledged. According to Shanock et al. (2012) there are a variety of limitations to using difference scores. For starters, using difference scores do not tell us the extent to which each of the component measures contribute to the outcome variable. Reliability of difference scores is also put into question (Edwards, 1995). Shanock et al. recommend using polynomial regression due to being able to examine the extent to which each component measure contributes to variance in the outcome, helping to overcome problems with ambiguous interpretation and confounded effects.

Lastly, a potential limitation in the current study is the use of the acceptability subscale from the Meta Evaluation Scales. For starters, Mayer \& Stevens (1994) completed two studies in which the coefficient alpha reliabilities of the acceptability subscale were .75 and .78 which is adequate. Further, the measure did not fully capture the participants acceptance of emotions. Items include: "I'm not ashamed of my mood" and "I shouldn't feel this way" which appear to be measuring mood regulation rather than attitudes regarding emotions. Future studies may benefit from including a measure related to stigma about experiencing distress.

In general, future studies are needed. For starters, the current study focused on unpleasant emotions (e.g., sadness) in regard to depression, emotional intensity, acceptability of emotion, and emotional disclosure. The topic merits further investigation, specifically the role other emotions (e.g., disgust, sadness, amusement, embarrassment, etc.) may play with the previously mentioned variables. Secondly, the current study focused on events and emotional disclosure; however, who a person is can also determine whether the person is likely to emotionally disclose. Future studies may benefit from measuring participants' personality traits and characteristics in addition to the other variable. It would be interesting to explore the role participants traits and characteristics play on emotional intensity, acceptability of emotion, and emotional disclosure. 


\section{Implications for Counseling}

The results of this study provided important implications for counseling psychology. The findings suggest it is important for therapists to be aware of how depression symptoms and emotional intensity influence emotional disclosure. It is also important for therapists to be aware of how depression symptoms may influence the client's acceptability of emotions (Garrison et al., 2012). In regard to clients experiencing depression symptoms, it may be important for clinicians to know that clients with more symptoms of depression may have more difficulty disclosing. Further, the client experiencing depression symptoms may view events as more intense in comparison to other clients or their own interpretation. Clinicians may have to create different methods of encouraging depressed clients to disclose.

Since the present findings suggest individuals with depression experience higher levels of perceived intensity in regard to life events, clinicians may aim to reduce the perceived intensity of life events. Clinicians can utilize mindfulness interventions. A variety of research studies indicate mindfulness training plays a major role in facilitating effective regulation of negative emotions in the context of everyday life (Keng et al., 2021). Additionally, Keng et al.'s study finds that mindfulness-based stress reduction influences individuals negative emotions which further support past research.

Moreover, findings suggest that clients experiencing more depression symptoms may view emotions as less acceptable compared to clients with minor or no symptoms. Therefore, it may be important to help those clients become more tolerant or accepting of emotions. According to research, Acceptance and Commitment Therapy encourages nonjudgmental observation, mindfulness, and willingness which may be a helpful method in regard to altering acceptability of emotions (Campbell-Sills et al., 2006; Hayes et al., 1999; Segal et al., 2002). 


\section{REFERENCES}

Acar, D., \& Dirik, G. (2019). A current paradigm: written emotional disclosure. Psikiyatride Guncel Yaklasimlar, 11(1), 65-79.

American College Health Association (ACHA). (2017). National College Health Assessment II: Reference group executive summary. Hanover, MD: Author.

Baker, R., Holloway, J., Thomas, P. W., Thomas, S., \& Owens, M. (2004). Emotional processing and panic. Behavior Research and Therapy, 42(11), 1271-1287. https://doiorg.libproxy.lib.ilstu.edu/10.1016/j.brat.2003.09.002

Bakhshair, J., Bonnen, M., Asper, J., Sandulache, V., \& Badr, H. (2020). Emotional disclosure and cognitive processing in couples coping with head and neck cancer. Journal of Behavioral Medicine, 43(3), 411-425. https://doiorg.libproxy.lib.ilstu.edu/10.1007/s10865-019-00094-5

Barlow, D. H., Allen, L. B., \& Choate, M. L. (2016). Towards a unified treatment for emotional disorders. Behavior Therapy, 47(6), 838-853. https://doiorg.libproxy.lib.ilstu.edu/10.1016/j.beth.2016.11.005

Barr, L. K., Kahn, J. H., \& Schneider, W. J. (2008). Individual differences in emotional expression: Hierarchical structure and relations with psychological distress. Journal of Social and Clinical Psychology, 27(10), 1045-1077. https://doi.org/10.1521/jscp.2008.27.10.1045

Bieling, P. J., Milosevic, I., \& McCabe, R. E. (2014). Groups for depression. In J. L. DeLuciaWaack, C. R. Kalodner, \& M. T. Riva (Eds.), Handbook of group counseling and psychotherapy (pp. 367-380). Sage Publications, Inc. https://doi.org/10.4135/9781544308555.n29 
Bourne, L. (2021). Strengthening mental health awareness of university students using an online training module [ProQuest Information \& Learning]. In Dissertation Abstracts International: Section B: The Sciences and Engineering (Vol. 82, Issue 2-B).

Bylsma, L. M., Taylor-Clift, A., \& Rottenberg, J. (2011). Emotional reactivity to daily events in major and minor depression. Journal of Abnormal Psychology, 120(1), 155-167. http://dx.doi.org/10.1017/S0033291717002781

Campbell-Sills, L., Barlow, D. H., Brown, T. A., \& Hoffmann, S. G. (2006). Acceptability and suppression of negative emotion in anxiety and mood disorders. Emotion, 6(4), 587-595. https://doi-org.libproxy.lib.ilstu.edu/10.1037/1528-3542.6.4.587

Campbell-Sills, L., \& Barlow, D. H. (2007). Incorporating Emotion Regulation into Conceptualizations and Treatments of Anxiety and Mood Disorders. In J. J. Gross (Ed.), Handbook of emotion regulation (pp. 542-559). The Guilford Press.

Cutts, J. K. (2018). Online written disclosure: effects on psychological well-being in individuals with infertility, Dissertation Abstracts International Section C: Worldwide, 75(4-C).

Edwards, J. R. (1995). Alternatives to difference scores as dependent variables in the study of congruence in organizational research. Organization Behavior and Human Decision Processes, 64(3), 307-324. https://doi.org/10.1006/obhd.1995.1108

English, I., \& Campbell, D. G. (2019). Prevalence and characteristics of universal depression screening in US college health centers. Families, Systems, \& Health, 37(2), 131-149. https://doi-org.libproxy.lib.ilstu.edu/10.1037/fsh0000411 
Enneking, V., Krüssel, P., Zaremba, D., Dohm, K., Grotegerd, D., Förster, K., Meinert, S., Bürger, C., Dzvonyar, F., Leehr, E. J., Böhnlein, J., Repple, J., Opel, N., Winter, N. R., Hahn, T., Redlich, R., \& Dannlowski, U. (2019). Social anhedonia in major depressive disorder: A symptom-specific neuroimaging approach. Neuropsychopharmacology, 44(5), 883-889. https://doi-org.libproxy.lib.ilstu.edu/10.1038/s41386-018-0283-6

Ernst, M., Kallenbach-Kaminski, L., Kaufhold, J., Negele, A., Bahrke, U., Hautzinger, M., Beutel, M. E., \& Leuzinger-Bohleber, M. (2019). Suicide attempts in chronically depressed individuals: What are the risk factors? Psychiatry Research. https://doiorg.libproxy.lib.ilstu.edu/10.1016/j.psychres.2019.112481

Esterling, B. A., Antoni, M. H., Fletcher, M. A., Margulies, S., \& Schniederman, N. (1994). Emotional disclosure through writing or speaking modulates latent Epstein-Barr virus antibody titers. Journal of Consulting and Clinical Psychology, 62(1), 130-140. https://doi-org.libproxy.lib.ilstu.edu/10.1037/0022-006X.62.1.130

Francis, M. E., \& Pennebaker, J. W. (1992). Putting stress into words: The impact of writing on psychological, absentee and self-reported emotional well-being measures. American Journal of Health Promotion, 6, 280-287. https://doi.org/10.4278/0890-1171-6.4.280

Frazier, P. A., Tix, A. p., \& Barron, K. E. (2004). Testing moderator and mediator effects in counseling psychology research. Journal of Counseling Psychology, 51(1), 115-134. https://doi-org.libproxy.lib.ilstu.edu/10.1037/0022-0167.51.1.115

Garrison, A. M., \& Kahn, J. H. (2010). Intraindividual relations between the intensity and disclosure of daily emotional events: The moderating role of depressive symptoms. Journal of Counseling Psychology, 57(2), 187-197. doi: 10.1037/a0018386 
Garrison, A. M., Kahn, J. H., Eric, S. M., \& Florczak, M. A. (2012). Disentangling the effects of depression symptoms and adult attachment on emotional disclosure. Journal of Counseling Psychology, 59(2), 230-239. https://doi:10.1037/a0026132

Gross, J. J. (1999). Emotion regulation: Past, present, future. Cognition and Emotion, 13(5), 551573. https://doi-org.libproxy.lib.ilstu.edu/10.1080/026999399379186

Gross, J. J. (2002). Emotion Regulation: Affective, cognitive, and social consequences. Psychophysiology, 39(3), 281-291. https://doiorg.libproxy.lib.ilstu.edu/10.1017/S0048577201393198

Guo, S., Nguyen, H., Weiss, B., Ngo, V. K., \& Lau, A. S. (2015). Linkages between mental health need and help-seeking behavior among adolescents: Moderating role of ethnicity and cultural values. Journal of Counseling Psychology, 62(4), 682-693. https://doiorg.libproxy.lib.ilstu.edu/10.1037/cou0000094

Hayes, S. C., Strosahl, K. D., \& Wilson, K. G. (1999). Acceptance and commitment therapy: An experimental approach to behavior change. New York: Guilford Press.

Hemenover, S. H. (2003). The good, the bad, and the healthy: Impacts of emotional disclosure of trauma on resilient self-concept and psychological distress. Personality and Social Psychology Bulletin, 29(10), 1236-1244. https://doiorg.libproxy.lib.ilstu.edu/10.1177/0146167203255228

Kahn, J. H., \& Garrison, A. M. (2009). Emotional self-disclosure and emotional avoidance: relations with symptoms of depression and anxiety. Journal of Counseling Psychology, 56(4), 573-584. https://doi-org.libproxy.lib.ilstu.edu/10.1037/a0016574 
Kahn, J. H., \& Hessling, R. M. (2001). Measuring the tendency to conceal versus disclose psychological distress. Journal of Social and Clinical Psychology, 20(1), 41-65. https://doi-org.libproxy.lib.ilstu.edu/10.1521/jscp.20.1.41.22254

Kahn, J. H.. Hucke, B. E., Bradley, A. M., Glinski, A. J., \& Malak, B. L. (2012). The Distress Disclosure Index: A research review and multitrait-multimethod examination. Journal of Counseling Psychology, 59(1), 134-149. https://doi:10.1037/a0025716

Kahn, J. H., Tobin, R. M., Massey, A. E., \& Anderson, J. A. (2007). Measuring emotional expression with linguistic inquiry and word count. The American Journal of Psychology, 120(2), 263-286.

Kearns, M. C., Edwards, K. M., Calhoun, K. S., \& Gidycz, C. A. (2010). Disclosure of sexual victimization: The effects of pennebaker's emotional disclosure paradigm on physical and psychological distress. Journal of Trauma \& Dissociation, 11(2), 193-209. https://doi-org.libproxy.lib.ilstu.edu/10.1080/15299730903502979

Kelly, J. E., Lumley, M. A., \& Leisen, J. C. C. (1997). Health effects of emotional disclosure in rheumatoid arthritis patients. Health Psychology, 16(4), 331-340. https://doiorg.libproxy.lib.ilstu.edu/10.1037/0278-6133.16.4.331

Keng, S.-L., Tong, E. M. W., Yan, E. T. L., Ebstein, R. P., \& Lai, P.-S. (2021). Effects of mindfulness-based stress reduction on affect dynamics: A randomized controlled trial. Mindfulness, 12(6), 1490-1501. https://doiorg.libproxy.lib.ilstu.edu/10.1007/s12671-021-01617-5

Kenny, D. A., Kashy, D. A., \& Bolger, N. (1998). Data analysis in social psychology. In D. T. Gilbert, S. T. Fiske, \& G. Lindzey (Eds.), The handbook of social psychology (4th ed., pp. 233-265). New York: Oxford University Press. 
Kessler, R. C. (1997). The effects of stressful life events on depression. Annual Review of Psychology, 48, 191-214. https://doiorg.libproxy.lib.ilstu.edu/10.1146/annurev.psych.48.1.191

Kessler, R. C, Berglund P, Demler O, et al: The epidemiology of major depressive disorder: results from the National Comorbidity Survey Replication (NCSR). JAMA 289(23):3095-3105, 2003

Kivity, Y., Tamir, M., \& Huppert, J. D. (2016). Self-acceptance of negative emotions: The positive relationship with effective cognitive reappraisal. International Journal of Cognitive Therapy, 9(4), 279-294. https://doiorg.libproxy.lib.ilstu.edu/10.1521/ijct_2016_09_10

Kokkonen, M., \& Pulkkinen, L. (2001). Examination of the paths between personality, current mood, its evaluation, and emotion regulation. European Journal of Personality, 15(2), 83-104. https://doi-org.libproxy.lib.ilstu.edu/10.1002/per.397

Kroenke K, Spitzer R L, Williams J B (2001). The PHQ-9: validity of a brief depression severity measure. Journal of General Internal Medicine, 16(9), 606-613. https://doiorg.libproxy.lib.ilstu.edu/10.1046/j.1525-1497.2001.016009606.x

Mayer, J. D., \& Stevens, A. A. (1994). An emerging understanding of the reflective (meta-) experience of mood. Journal of Research in Personality, 28(3), 351-373. https://doi.org/10.1006/jrpe.1994.1025.

Opre, A., Coman, A., Kallay, E., Rotaru, D., \& Manier, D. (2005). Reducing distress in college students by expressive writing. A pilot study on a Romanian sample. Cognitie Creier Comportament, 9(1), 53-64. 
Pennebaker, J. W., Kiecolt-Glaser, J. K., \& Glaser, R. (1988). Disclosure of traumas and immune function: Health implications for psychotherapy. Journal of Consulting and Clinical Psychology, 56(2), 239-245. https://doi-org.libproxy.lib.ilstu.edu/10.1037/0022006X.56.2.239

Pennebaker, J. W., \& Seagal, J. D. (1999). Forming a story: The health benefits of narrative. Journal of Clinical Psychology, 55(10), 1243-1254. https://doiorg.libproxy.lib.ilstu.edu/10.1002/(SICI)1097-4679(199910)55:10<1243::AIDJCLP6>3.0.CO;2-N

Petrie, K. J., Booth, R. J., Pennebaker, J. W., Davison, K. P., \& Thomas, M. G. (1995). Disclosure of trauma and immune response to a hepatitis B vaccination program. Journal of Consulting and Clinical Psychology, 63(5), 787-792. https://doiorg.libproxy.lib.ilstu.edu/10.1037/0022-006X.63.5.787

Radloff, L. S. (1977). The CES-D scale: A self report depression scale for research in the general population. Applied Psychological Measurements, 1(3), 385-401. https://doiorg.libproxy.lib.ilstu.edu/10.1177/014662167700100306

Recovery Brands LLC. (2020). Types of Stressors (Eustress vs. Distress). Retrieved September 14, 2020, from https://www.mentalhelp.net/stress/types-of-stressors-eustress-vs-distress/

Reis, H. T., \& Gable, S. L. (2000). Event-sampling and other methods for studying everyday experience. In H. T. Reis \& C. M. Judd (Eds.), Handbook of research methods in social and personality psychology (pp. 190-222). Cambridge University Press.

Rimé, B. (1995). Mental rumination, social sharing, and the recovery from emotional exposure. In J. W. Pennebaker (Ed.), Emotion, disclosure, \& health (pp. 271-291). American Psychological Association. https://doi.org/10.1037/10182-013 
Rodríguez, M. R., Nuevo, R., Chatterji, S., \& Ayuso-Mateos, J. L. (2012). Definitions and factors associated with subthreshold depressive conditions: A systematic review. $B M C$ Psychiatry, 12. https://doi-org.libproxy.lib.ilstu.edu/10.1186/1471-244X-12-181

Rottenberg, J. (2005). Mood and emotion in major depression. Current Directions in Psychological Science, 14(3), 167-170. doi:10.1111/j.0963- 7214.2005.00354.x

Rottenberg, J. (2007). Major Depressive Disorder: Emerging Evidence for Emotion Context Insensitivity. In J. Rottenberg \& S. L. Johnson (Eds.), Emotion and psychopathology: Bridging affective and clinical science (pp. 151-165). American Psychological Association. https://doi.org/10.1037/11562-007

Rude, S. S., \& McCarthy, C. T. (2003). Emotional functioning is depressed and depressionvulnerable college students. Cognition \& Emotion. 17(5), 799-806. https://doiorg.libproxy.lib.ilstu.edu/10.1080/02699930302283

Segal, Z. V., Williams, J. M. G., \& Teasdale, J. D. (2002). Mindfulness-based cognitive therapy for depression: A new approach to preventing relapse. New York: Guilford Press.

Shanock, L. R., Baran, B. E., Gentry, W. A., Pattison, S. C., \& Heggestad, E. D. (2010). Polynomial regression with response surface analysis: A powerful approach for examining moderation and overcoming limitations of difference scores. Journal of Business and Psychology, 25(4), 543-554. https://doiorg.libproxy.lib.ilstu.edu/10.1007/s10869-010-9183-4

Smith, L. J., Paulus, D. J., Gallagher, M. W., Norman, S. B., Tran, J. K., \& Vujanovic, A. A. (2019). Perceived stress and probable alcohol misuse in firefighters: The role of posttraumatic stress. International Journal of Stress Management, 26(4), 367-377. https://doi-org.libproxy.lib.ilstu.edu/10.1037/str0000118 
Stiles, W. B. (1987). "I have to talk to somebody": A fever model of disclosure, In V. J. Derlega \& J. H. Berg (Eds.), Self-disclosure: Theory, research, and therapy (pp.257-282). New York: Plenum Press.

Stiles, W. B. (1995). Disclosure as a speech act: Is it psychotherapeutic to disclose? In J. W. pennebaker (Ed.). Emotion, disclosure, \& health (pp. 71-91). American Psychological Association. https://doi.org/10.1037/10182-004

Sultan, S., \& Chaudry, H. (2008). Gender-based differences in the patterns of emotional selfdisclosure. Pakistan Journal of Psychological Research, 23(3-4), 107-122.

Zivin, K., Eisenberg, D., Gollust, S. E., \& Golberstein, E. (2009). Persistence of mental health problems and needs in a college student population. Journal of Affective Disorders, 117(3), 180-185. http://dx.doi.org/10.1016/j.jad.2009.01.001

Weinberger, A. H., Gbedemah, M., Martinez, A. M., Nash, D., Galea, S., \& Goodwin, R. D. (2018). Trends in depression prevalence in the USA from 2005 to 2015: widening disparities in vulnerable groups. Psychological Medicine, 48(8), 1308-1315. http://dx.doi.org/10.1017/S0033291717002781 


\section{APPENDIX A: PARTICIPANT CONSENT FORM}

You are being asked to participate in a research study conducted by Brandie Vera, a Graduate student under the direction of Dr. Jeffrey Kahn in the clinical-counseling psychology program. The purpose of this study is to examine depression symptoms, emotion-context intensity, acceptability of emotions, and emotional disclosure.

\section{Why are you being asked?}

You have been asked to participate because you are a student taking a psychology course in which credit is offered for research participation. Your participation in this study is voluntary. You will not be penalized if you choose to skip parts of the study, not participate, or withdraw from the study at any time.

\section{What would you do?}

If you choose to participate in this study, you will complete an online survey. In total, your involvement in this study will last approximately 30 minutes.

\section{Are any risks expected?}

There is a small risk that you will come across a question or answer choice that you find unpleasant, upsetting, or otherwise objectionable. To reduce this risk, we remind you that you do not have to answer any questions you feel uncomfortable answering.

\section{Will your information be protected?}

Your responses will be anonymous. To ensure that your responses are not tied to your identity, we will not collect identifying information. The findings from this study may be presented at a professional conference or in a scientific journal. In such an article, participants would be identified in general terms as students at Illinois State University.

\section{Will you receive anything for participating?}

By taking this online survey, you will be offered $1 / 2$ point of credit through the Sona system. In order to receive compensation, at the end of the survey you will be taken to a separate page to enter your contact information. This information will be kept entirely separate from the survey and your responses. Once the compensation is distributed, we will delete your contact information.

\section{Who will benefit from this study?}

A benefit to you for participating is that, when you reach the end of the questionnaire, you will have an opportunity to learn more about this research, which can help you in your psychology course. By completing the questionnaires, you may also learn more about yourself.

\section{Whom do you contact if you have any questions?}

If you have any questions about the research or wish to withdraw from the study, contact Brandie Vera at bcvera@ilstu.edu. If you have any questions about your rights as a participant, or if you feel you have been placed at risk, contact the Illinois State University Research Ethics \& Compliance Office at (309) 438-5527 or IRB@ilstu.edu 


\section{APPENDIX B: DEBRIEFING}

You are now finished with the survey.

The purpose of the questionnaire you just completed was to learn how emotion-context intensity and acceptability of emotions impacts the relationship between depression symptoms and emotional disclosure. Previous research indicates that depression symptoms are associated with tendencies to emotionally disclose; in other words, people who have experience more depression symptoms have a harder time emotionally disclosing. The goal of our research is to find out which specific aspects of depression are associated with less emotional disclosure. We believe that this research may be useful in helping people with depression understand their tendencies to not emotionally disclose.

Your participation has been very helpful to us, and we thank you. If you would like to learn more about this research, you can contact Brandie Vera, graduate student, at bcvera@ilstu.edu or Committee chair member, Dr. Jeffrey Kahn, professor of psychology at jhkahn@ilstu.edu or (309) 438-7939.

In this study it is critical that future participants do not know anything about the study until after they have participated in it. This is necessary in order to prevent people from responding in a biased manner. Therefore, it is extremely important that you keep information about your experience today from anyone else who may participate. 